\title{
РОЛЬ ДВИГАТЕЛЬНОЙ АКТИВНОСТИ В РЕЖИМЕ ДНЯ СТУДЕНТОВ 18-20 ЛЕТ
}

\section{THE ROLE OF MOTOR ACTIVITY IN THE DAY MODE OF STUDENTS 18-20 YEARS \\ Sh. Shamsutdinov \\ A. Sultanov \\ V. Saifutdinov}

Summary: A healthy nation represented by student youth is today one of the priorities of our state. Studying motor activity in the day mode provides an opportunity to optimize physical activity for a certain contingent of students. All these factors clearly predetermine the active scientific search for effective means and methods that contribute to the process of not only mental development, but also qualitative physical and functional development, eradicating these factors of disease that can be corrected through exercise.

Keywords: student, physical activity, occupation, physical culture, sports.

\author{
Шамсутдинов Шамиль Абдулович \\ к.п.н., дочент, Стерлитамакский филиал Башкирский \\ государственный университет \\ saleev-eldar@mail.ru \\ Султанов Ахмад Джуракулович \\ Дочент, Стерлитамакский филиал Башкирский \\ государственный университет \\ Сайфутдинов Вахит Варисович \\ Дочент, Стерлитамакский филиал Башкирский \\ государственный университет
}

Аннотация: Здоровая нация в лице студенческой молодежи на сегодняшний день одно из приоритетных направлений нашего государства. Изучение двигательной активности в режиме дня дает возможность оптимизировать физическую нагрузку для определенного контингента студентов.

Все эти факторы явно предопределяют активный научный поиск эффективных средств и методов, способствующих повышению процесса не только умственного развития, но и качественного физического и функционального развития, искореняя этим те факторы заболевания, которые можно исправить путем физических упражнений.

Ключевые слова: студент, физическая нагрузка, занятие, физическая культура, спорт.

ли включать шагомер после пробуждения и отключать перед сном. Каждый испытуемый студент заносил результаты шагомера ежедневно в дневник самоконтроля, кроме того, велись записи самооценки выраженности потребности в двигательной активности (ПДА) в бальной системе: 0-ПДА не возникала потребность; 1- возникла слабовыраженная ПДА и 2- выраженная ПДА.

Измерения проводились ежедневно в течении недели. На основании данных показателей определялась средне-суточная активность, а также суточная активность в день занятий ОФК и на следующий день. Результаты обрабатывались с применением параметрических методов Стьюдента с определением средней арифметической (М), ошибки средней арифметической (m), переменной Стьюдента t с оценкой достоверности по критерию значимости р. Различия между группами признаков считались достоверными при $р<0,05$ (Шевченко И.Т. и др., 1970; Гельман В.Д., 2001).

\section{Результаты и их обсуљкения.}

Материал и методы исследования. В исследовании приняли участие 124 студента 1-2 х курсов СФ Баш ГУ (муж.18-20 лет) не занимающих в спортивных секциях. Двигательная активность в режиме дня измерялась с помощью шагомера [3]. Перед началом исследования со студентами провели инструктаж и порекомендова-
Двигательная активность студентов имела существенные индивидуальные отличия, варьируя от 2323 до 18989 шагов в сутки. Распределение этой активности было близким к нормальному. Ее среднесуточный уровень - 10250 395 шагов в сутки. В день занятий по пред- 
мету «Общая физическая культура» двигательная активность студентов естественно повышалась до $13300 \pm 484$ $(p<0,001)$, и на следующий день наблюдений снижалась до среднесуточной (рис 1).

По результатам самооценки, потребность в двигательной активности статистически достоверно повышалась в день занятий по предмету «Общая физическая

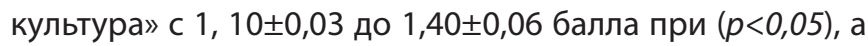

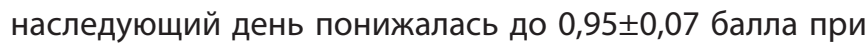
$(p<0,05)$, что однако, было не ниже среднесуточного показателя $(p>0,05)$.

Методом персентилей были установлены критерии разделения всей выборки на группы с различной выраженностью двигательной активности. В первую группу, «активных», с высокой двигательной активностью вошли студенты с показателем, большим или равным 13000 шагов в среднем за сутки, во вторую группу, «пассивных», - с показателем, меньшим или равным 6000 шагам в среднем за сутки $[4,5]$.

Динамика двигательной активности студентов указанных групп имела некоторые особенности в сравнении с изменением этого показателя для общей выборки (рис 1). Так снижение двигательной активности студентов первой группы в день, следующий после занятий ОФК, было более интенсивным, чем в общей выборке и ее уровень отличался не только от уровня в день занятий по ОФК, но и от среднесуточного показателя. В отличии от общей выборки двигательная активность студентов второй группы в среднем за сутки и в день занятий по ОФК не различалась.

По данным самооценки, потребность в двигательной

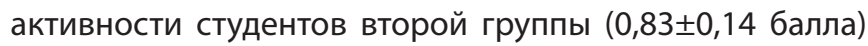
была ниже, чем в общей динамика этого показателя у «пассивных» студентов отличалась от таковой в общей выборке, существенно (более чем в 2 раза) снижаясь в день, следующий за днем занятий по физвоспитанию.

Обсуждение результатов. В ряде работ представлен фактический материал, свидетельствующий об индивидуальных различиях объема суточной двигательной активности [6]. Большинство этих результатов получено при наблюдении за детьми младшего школьного возраста. Наши данные подтверждают указанную закономерность. Общая двигательная активность мужчин 18-20 лет характеризуется постоянством индивидуального суточного объема при многодневной регистрации. Однако индивидуальная вариабильность этого показателя в наших исследованиях характеризовалась снижением минимального и максимального значения двигательной активности по сравнению с наблюдаемой у детей различного возраста [7, 8], и взрослых - работников умственного труда $[2,5]$. Это свидетельствует о большей подтвержденности студентов социальным факторам, приводящим к гипокинезии.

Согласно нашим представлениям, объем двигательной активности регулируется автоматически, благодаря механизму, в основе которого лежит потребность в движении. О наличии потребности в двигательной активности, аналогичный другим потребностям организма, высказывались и другие авторы [1]. В связи с этим интересными представляются наши данные о самооценке потребности в движении студентов. Они показали, что студенты, распределенные с помощью персентилей на две группы с противоположной выраженностью двигательной активности, различались между собой и по субъективной самооценке потребности в движении. Следовательно, объективно существующий двигательный объем двигательной активности отражается на субъективной самооценке потребности в движении.

В соответствии с современным подходом [4], общую двигательную активность можно разделить на облигатную, или навязанную и факультативную. Физиологическое значение последней заключается в поддержании постоянства суточного объема активности за счет компенсаторного повышения или снижения факультативной составляющей на навязывание двигательного режима. Вероятно, нагрузка на занятиях ОФК для студентов с низкой активностью превышает оптимум и поэтому

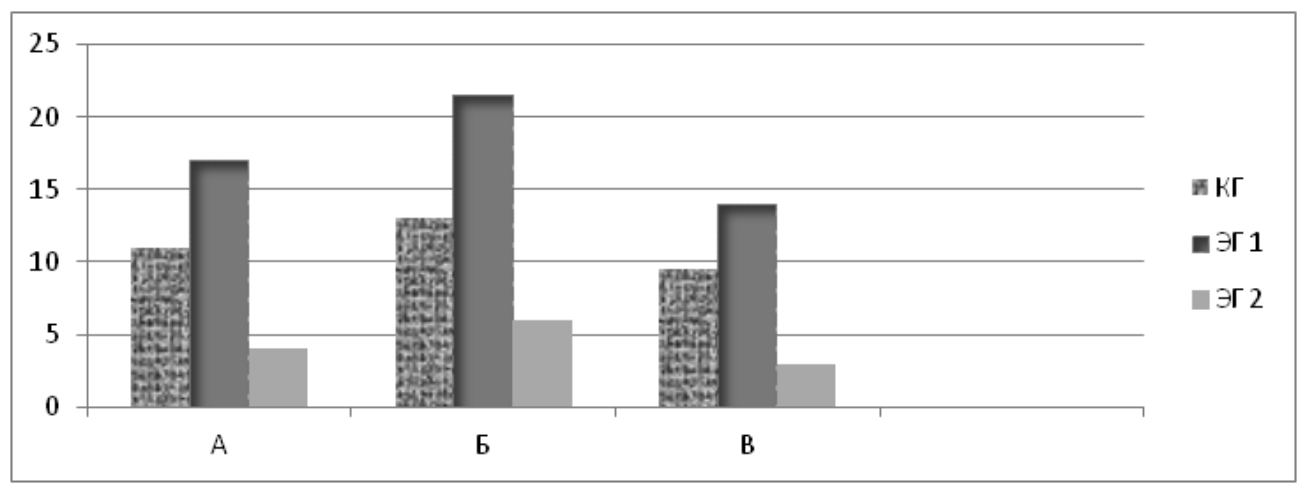

Рис. 1. Динамика двигательной активности студентов 18-20 лет. 
организм стремится сохранить постоянство суточного объема за счет снижения факультативной активности в оставшееся после занятий время суток. Только так можно объяснить отсутствие у «пассивных» студентов прироста двигательной активности и ее повышения у «активных» в день занятия при одинаковой нагрузке. Снижение у «пассивных» студентов субъективной самооценке потребности в движении, на ряду с двигательной активностью на следующий после занятия день, свидетельствует о том, что для их восстановления необходим еще один «компенсаторный» день.

Представленные данные указывают на необходимость индивидуального подхода к дозированию нагрузки на занятиях по ОФК для студентов с различным уровнем двигательной активности. В качестве индикатора соответствия объема активности потребности организма может быть использована субъективная самооценка потребности в ней.

\section{Выво}

1. Объем суточной двигательной активности студентов характеризуется существенными индивидуальными различиями. Для студентов с низкой выраженностью этого показателя характерна низкая самооценка потребности в движении.

2. Занятия по «Общей физической культуре» оказывают моделирующее влияние на двигательную активность и самооценку потребности в движении у студентов. В день занятия ОФК эти показатели повышаются.

3. Занятия по ОФК неодинаково действуют на двигательную активность и самооценку потребности в ней у студентов с противоположной выраженностью объема суточных локомоций. Студенты с низкой выраженностью этого показателя отличаются тем, что их двигательная активность не возрастает в день проведения занятий ОФК, а самооценка потребности в движении существенно снижается на следующий день после занятий.

\section{ЛИТЕРАТУРА}

1. Акамов В.В., Евдокимов Н.И. Организационно-методические основы физического воспитания студентов педагогического вуза //В.В. Акамов, Н.И. Евдокимов - М., 2010. - № 6. С. - 293-296.

2. Васенков Н.В., Фазлеева Е.В. Гипокиннезия как одна из причин ухудшения здоровья студентов. //Вестник НЦБЖД (научный центр безопасности жизнедеятельности) 2013. № 1 (15) с. 50-54.

3. Григорьева 0.В. Психофизиологическое обоснование роли двигательной активности для здоровья человека. //Карельский научный журнал 2014. №

4. Имнаев Ш.А. Основные направления повышения эффективности физического воспитания студенческой молодежки //Ш.А. Имнаев, А.И. Осадчий, Р.В. Стрельников, Ю.И. Журавлева. Вестник Пятигорского государственного лингвистического университета. - М.,2008. - № 3. - С. - 229-234.

5. Литовченко 0.Г. Особенности морфофункционального и психо-физиологического развития уроженцев Среднего Приобья в возрасте 7-20 лет: дис. ... д-ра биол. наук. - Челябинск, 2009. - 285 с.

6. Мардиян М.А. Современные проблемы укрепления здоровья подростков и вопросы профилактики /М.А. Мардиян// - М.: Книга. 2005. С. - 120-122.

7. Миронова Г.Л. Роль физической культуры и спорта в подготовке к профессиональной деятельности выпускников вузов //Актуальные проблемы и перспективы физкультурного образования в вузах: Материалы международной научно-практической конференции. - Волгоград, 2004. - № 2. С. - 240-243.

8. Розенфельд Л.Г. Здоровье студентов по данным субъективной оценки и факторы риска, влияющие на него / Л.Г. Розенфельд, С.А. Батрымбетова. // Здравоохранение Российской Федерации. 2008. № 4.-45с.

(c) Шамсутдинов Шамиль Абдулович (saleev-eldar@mail.ru), Султанов Ахмад Джуракулович, Сайфутдинов Вахит Варисович. Журнал «Современная наука: актуальные проблемы теории и практики» 